九州大学学術情報リポジトリ

Kyushu University Institutional Repository

\title{
Variation and Determinants of Rice Yields among Individual Paddy Fields : Case Study of a Large-Scale Farm in the Kanto Region of Japan
}

\section{Li, Dongpo}

Faculty of Agriculture, Kyushu University

Nanseki, Teruaki

Laboratory of Agricultural and Farm Management, Division of Agricultural and Resource

Economics, Department of Agricultural and Resource Economics, Faculty of Agriculture, Kyushu University

Matsue, Yuji

Faculty of Agriculture, Kyushu University

Chome i, Yosuke

Laboratory of Agricultural and Farm Management, Division of Agricultural and Resource Economics, Department of Agricultural and Resource Economics, Faculty of Agriculture, Kyushu University

他

https://doi.org/10.5109/1564104

出版情報: 九州大学大学院農学研究院紀要. 61 (1)，pp.205-214，2016-02-29. Faculty of Agriculture, Kyushu University

バージョン：

権利関係 : 


\title{
Variation and Determinants of Rice Yields among Individual Paddy Fields: Case Study of a Large-Scale Farm in the Kanto Region of Japan
}

\section{Dongpo LI ${ }^{1}$, Teruaki NANSEKI*, Yuji MATSUE ${ }^{1}$, Yosuke CHOMEI and Shuichi YOKOTA ${ }^{2}$}

\author{
Laboratory of Agricultural and Farm Management, Division of Agricultural and Resource Economics, \\ Department of Agricultural and Resource Economics, Faculty of Agriculture, \\ Kyushu University, Fukuoka 812-8581, Japan \\ (Received October 21, 2015 and accepted November 19, 2015)
}

\begin{abstract}
This study aims to identify the variation and determinants of rice yield measured by IT combine, among different rice yields within large-scale farms. In addition to the yield of the paddy with $15 \%$ of moisture, unsorted and sorted brown rice, variations of concerning ratios are studied as well. The sample includes 351 paddy fields from a farm corporation scaled over 113 ha, locating in the Kanto region of Japan. The candidate determinants include the field area and condition, nitrogen amount, time of transplanting or seeding, stage-specific growth indictors for the contain of chlorophyll, number of panicles, plant height, and leaf plate value. In addition, soil properties, average temperature and solar radiation are incorporated. Meanwhile, varieties, cultivation methods and soil types are adopted as dummy variables. The empirical analysis is conducted using a multivariate linear regression, with logarithmic transformations of the continuous variables. The estimation result indicates that panicle numbers in full-heading stage and transplanting or sowing time are the most important continuous determinants, following by nitrogen amount, humus content, and so forth. Within the significant discrete determinants, Akidawara and Milky queen are measured as productive and unproductive variety, respectively; while the well-drained direct sowing method is identified as negatively affecting the yield.
\end{abstract}

Key words: Determinant, sorted brown rice, smart agriculture, variation, yield

\section{INTRODUCTION}

Since recapturing the regime in end of 2012, the LDP government has been pushing ahead serial policies of Proactive Agriculture, Forestry and Fisheries, to increase the efficiency and competitiveness with these sectors in Japan. As to agriculture, it is essential to reduce the production costs and improve the yields, through the fiscal subsides to adopt efficient technologies, equipments, managerial models, etc. To increase rice yield and hence reduce the average production costs, the government has declared that by 2018, the Acreage Reduction of rice adopted since early 1970s will be abolished, to expand efficient production and exports actively with improved international competitiveness (JEN, 2013).

As the staple crop in Japan, rice accounted for the largest proportion in gross agriculture output of $21.03 \%$ by 2013 (MAFF, 2014a). After the post-war high economic growth, the rapidly expanded western diet had changed Japanese food consumption with increasing animal products such as meat, dairy products, eggs, oils and fats. Together with the increasing percentage of the elderly and decreasing population, the average annual consumption of sorted brown rice had decreased from $111.7 \mathrm{~kg}$ per capita in 1965, to $55.2 \mathrm{~kg}$ per capita in 2014 (MAFF, 2014b). Simultaneously, rice production has been decreasing and dragged down the agricultural growth to a large extent (Ohizumi, 2014).

\footnotetext{
Faculty of Agriculture, Kyushu University

Yokota Farm Co. Ltd., Ryugasaki, Ibaraki Prefecture

* Corresponding author (E-mail: nanseki@agr.kyushu-u.ac.jp)
}

In Japan, rice yield is measured by the sorted brown rice grains with the thickness no less than a certain threshold, usually $1.70 \mathrm{~mm}$ as cited here. In 2014, the yield of sorted brown rice was 8.43 million ton, decreased by $40.27 \%$ from 11.83 million ton in 1985 . Within the same period, the planted area of paddy has decreased by $45.58 \%$ from 2.29 million ha to 1.57 million ha. Since 2000 , the average yield of the sorted brown rice has been stagnant on approximately 5300-5400 kg per hectare. In 2014, the average yield of the sorted brown rice was $5360 \mathrm{~kg}$ per hectare (MAFF, 2015), while the counterpart data in the US was $7263 \mathrm{~kg}$ per hectare (USDA, 2014). Meanwhile, the paddy production in Japan is faced with high costs. In 2013, the average production costs of the sorted rice in Japan was 258 JPY per kg (MAFF, 2014c), much higher than that of the US, which is merely $35 \mathrm{JPY}$ per $\mathrm{kg}$ on average (USDA, 2014). To be noticed, different with Japan, rice yield is measured by paddy, the raw rice grain without threshing the hull, in many other countries include the US, China and Korea. Thus for better comparison, the above rice yield of the US has been transformed from paddy to sorted paddy rice, by 1: 0.8 (MAFF, 2014d; Yaguchi, 2012). According to the Japan Revitalization Strategy released in 2014, the costs of paddy production need to be reduced by $40 \%$ in the next 10 years, compared with the current national average level (PMJHC, 2014).

Within the latest decades, agricultural production corporations have made dramatic growth, from 2740 in 1970, to 14333 in 2014 (MAFF, 2014e), and have become important paddy producers. The major reasons of this boom include that different from family management, agricultural production corporations possess larger ara- 
ble lands and stronger managerial ability, easier access to credit, diversified business development, better welfare and hence sufficient HR. Nevertheless, such largescale farms usually possess scattering paddy fields, with different scales, soil properties, altitude, humidity, daylighting, etc (JSAI, 2014: p128). At the same time, in an effort to cope with the problems relate to agriculture, food and environment, GAP (Good Agriculture Practice) has spread in Japan. With respect to paddy production, GAP can improve people's working and consuming condition, environmental protection through appropriate application of agro-chemicals and proper concerns about biodiversity, and food safety free of contamination and being balanced in nutrition (Li et al., 2014). In this circumstance, to increase the yield with saved costs of paddy production subject to GAP, ICT (Information Communication Technology) has been adopted and promoted, to process the enormous amount of information in sectors of innovational cultivation, production and managerial technologies (Nanseki, 2015; JSAI, 2014).

This research is part of the NoshoNavi1000, a projects funded by the Japanese Ministry of Agriculture, Forestry and Fisheries (MAFF). Represented by Kyushu University, the project consortium includes four agricultural production corporations with 1000 paddy fields scaled over 330 ha in total, two technological companies, five institutes and two universities (Nanseki, 2015). It aims to develop and demonstrate the smart paddy agriculture models, implemented by agricultural production corporations, with the integration of ICT agro-machinery, field sensors, visualization farming and skill-transferring system. In this study, we investigate the variation and determinants of rice yield measured by IT combine, among 351 paddy fields of different planting conditions, within a large-scale farm from Ibaraki Prefecture, Kanto Region of Japan. Different from most the prior studies using experimental data, we use yield data measured by IT combine in the fields of a large-scale farm, with the cooperation of farm managers and field-work practitioners.

\section{MATERIALS AND METHODS}

\section{Yield measurement and estimation}

According to the national standards of brown rice inspection of Japan (MAFF, 2014f), the paddy yield used in the following analyses is converted by $15 \%$ of moisture content. By contrast, the paddy before the conversion is named as raw paddy, weight and moisture content of which applied here are monitored directly by IT combine equipped with the GNSS (Global Navigation Satellite System, H. Isemura et al., 2015), and hereby with higher accuracy, comparing with the estimated weight of brown rice by sampling. Calculation of the rice yield with all of the 351 fields is shown in Table 1 . Incidentally, rice yield is determined by the following four factors: panicle number, spikelet number per panicle, ratio of filled grains and grain weight (CSSJ, 2002: p522).

In Japan, rice yield, as summarized above, refers to the weight of sorted brown grains, while it is presented by weight of paddy grains in most of the other countries. The difference is generated from a complex process of measuring the rice yield, incorporating different conceptions and ratios. As shown in Fig. 1, we estimated the paddy yield of $15 \%$ of moisture, using the data of raw paddy and average moisture, measured by on-farm IT combines. Then, samples about $2 \mathrm{~kg}$ from each paddy field was gathered and hulled, based on which the weight of the brown rice were measured. In succession, the ratio of brown rice and hence the yield of the unsorted brown rice were estimated for each paddy field. At the same time, the hulled samples were sent to the laboratory in Kyushu University, where the brown rice grains thicker than $1.85 \mathrm{~mm}$ were sorted out using grain-sorting machine, using another sample of $0.6 \mathrm{~kg}$. Finally, yield of the sorted brown rice was estimated by multiplying the yield of brown rice and ratio of sorted grains. For each paddy field, calculation of rice yields and the summary statistics of concerning indices are shown in Table 1.

\section{Continuous explanatory variables}

To outline the production and present the candidate yield determinants in the sampled paddy fields, we build an indicator system of 48 continuous variables, from the perspectives of field area and condition, nitrogen amount, time of transplanting or seeding, to the stagebased growth indictors. In addition, soil properties, average temperature and solar radiation are incorpo-

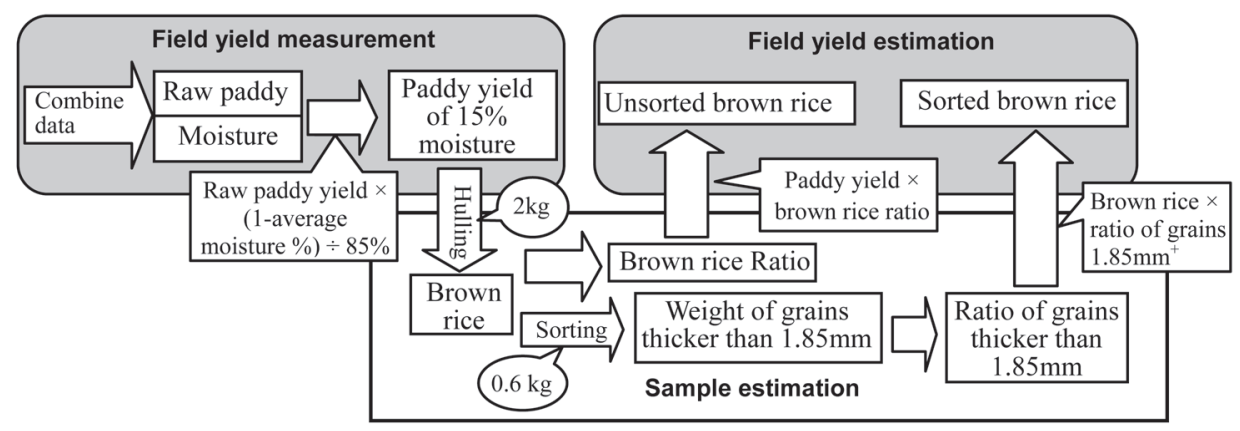

Fig. 1. Process of estimating the sorted brown rice yield. 
Table 1. Calculation of rice yields and the summary statistics

\begin{tabular}{|c|c|c|c|c|c|c|c|c|c|}
\hline Field & $\begin{array}{l}\text { Raw yield } \\
\text { (kg) }\end{array}$ & $\begin{array}{c}\text { Average } \\
\text { moisture } \\
(\%)\end{array}$ & $\begin{array}{l}\text { Total paddy yield }{ }^{\text {a }} \\
\text { (kg) }\end{array}$ & $\begin{array}{l}\text { Field } \\
\text { area } \\
\text { (ha) }\end{array}$ & $\begin{array}{c}\text { Average } \\
\text { paddy yield } \\
\text { (kg/ha) }\end{array}$ & $\begin{array}{l}\text { Unsorted } \\
\text { brown rice/ } \\
\text { paddy } \\
(\%)\end{array}$ & $\begin{array}{l}\text { Unsorted } \\
\text { brown rice } \\
\text { (kg/ha) }\end{array}$ & $\begin{array}{c}\text { Sorted/ } \\
\text { Unsorted } \\
\text { brown rice } \\
(\%)\end{array}$ & $\begin{array}{l}\text { Sorted brown } \\
\text { rice } \\
(\mathrm{kg} / \mathrm{ha})\end{array}$ \\
\hline & (a) & (b) & $(c)=a(100-b) / 85$ & (d) & $(e)=c / d$ & (f) & $(g)=e \times f / 100$ & (h) & (i) $=g \times h / 100$ \\
\hline No.1 & 7894.10 & 20.80 & 7355.40 & 1.03 & 7079.99 & 75.80 & 5366.64 & 90.88 & 4877.20 \\
\hline No.2 & 7555.40 & 23.30 & 6817.50 & 1.04 & 6557.18 & 75.00 & 4917.90 & 91.00 & 4475.29 \\
\hline$\cdots$ & $\ldots$ & $\ldots$ & $\cdots$ & $\cdots$ & $\ldots$ & $\cdots$ & $\ldots$ & $\ldots$ & $\ldots$ \\
\hline $\mathrm{N}$ & 351 & 351 & 351 & 351 & 351 & 345 & 345 & 349 & 344 \\
\hline Min. & 103.60 & 1.61 & 100.10 & 0.02 & 3484.44 & 70.61 & 3427.81 & 79.42 & 3074.65 \\
\hline Max. & 13388.40 & 31.60 & 12871.60 & 2.11 & 9945.93 & 83.80 & 7918.93 & 97.52 & 7462.00 \\
\hline Mean & 2383.68 & 21.91 & 2189.89 & 0.32 & 6904.42 & 77.87 & 5383.80 & 92.44 & 4976.76 \\
\hline Std.D. & 2384.19 & 3.26 & 2191.54 & 0.34 & 833.32 & 2.50 & 666.00 & 2.93 & 624.58 \\
\hline $\mathrm{CV}(\%)^{\mathrm{b}}$ & 100.02 & 14.89 & 100.08 & 105.88 & 12.07 & 3.22 & 12.37 & 3.17 & 12.55 \\
\hline
\end{tabular}

a: Converted yield by the moisture content of $15 \%$; b: The CV (coefficient of variation) represents the ratio of the standard deviation to the mean, and it is a useful statistic for comparing the degree of variation among data series

Source: survey conducted by the authors in 2014

rated to showcase impact of natural condition. The summary statistics are shown in Table 2.

(1) Fields property. The paddy fields vary in a large scope of area as revealed by the coefficient of variance, from 200 to $21148 \mathrm{~m}^{2}$ with an average of $3238 \mathrm{~m}^{2}$. Scores of field are evaluated by farm managers, considering the differences in height, water depth, water leakage, former crop, inletting water, soil fertility, illumination, and herbicides application. (2) Production management. The proxy variable of transplanting date is transformed through defining April 14 as 1 and June 22 as 70 for the all the 351 paddy fields. The nitrogen amounts are weighted means calculated according to the amounts and corresponding nitrogen contents of compost, compound chemical fertilizer, ammonium sulfate, and urea fertilizers. (3) Stage-specific growth indices. The stage covers from panicle-forming, full-heading, 10 days after full-heading and maturity. The growth indictors include the chlorophyll meter value of the soil and plant analyzer development (SPAD), number of stems or panicles per hill, plant height, and individual and community leaf plate value (LPV) by stage of panicle growth for the forming, heading, 10 days after full-heading, and maturity stages, as well as panicle length for the maturity stage only. (4) Temperature and solar radiation. With the global warming-up and climate changes, impacts of temperature and solar radiation on crop growth and yield have become increasingly concerned among scholars, e.g., Ohsumi et al. (2014), Deng et al. (2015). In our research project, we adopt the precision devices to collect continuous data of temperature and solar radiation in each hour. The data shown in Table 2 is the average of 20 days since heading, as this span of time is vital for starch accumulation (Asaoka et al., 1985). (5) Soil property analysis. Soil has been measured as an important determinant for paddy yield by many prior studies, e.g., Tsujimoto et al. (2009), from the function of permeability, heat-preservation, and the large amounts of fertilizing materials closely correlated with rice grain yields, from the surface to the deep soil layers. Based on the analysis results of specialist agencies, the soil properties are represented from five aspects: 1) fertility and texture include $\mathrm{pH}$, EC (electrical conduction), CEC (cation exchange capacity), humus, and phosphate absorption coefficient; 2) saturation, constitution and exchangeable amount of the base, by potassium, lime and magnesia; 3) inorganic nitrogen in forms of ammonium and nitrate; 4) effective phosphoric and silicic acid; 5) contents of other elements, including manganese, free iron oxide, soluble zinc and copper.

\section{Discrete explanatory variables}

In this research, we include the variety and cultivation method, to analyze determinants of rice yield, similar with some of the prior studies, include Nishiura and Wada (2012), Muazu et al. (2014), Ju et al. (2015). In addition, soil properties may affect rice growth and yield from the perspectives of nutrition content, water drainage and conservation, aeration, etc (CSSJ, 2002: p210). Therefore, we investigated the soil types of the sampled paddy fields, through referring to the Soil Information Navigation System of NIAES. A dummy variable named soil type is formulated, with the binary values of gray lowland soil and peat soil. The summary statistics of these variables are to be provided in the follow section.

\section{Statistical analysis}

Impact of the independent variables, including the discrete and continuous variables, on yield of sorted brown rice is analyzed using a multivariate regression. Values of the yield and the continuous variables are taken natural logarithmic transformations, to make easier interpretation of the regression coefficients in terms of elasticity (Gujarati, 2015: p44). All these analyses are performed using SPSS 23.0 for Windows, and the Backward procedure is used to select the significant determinants of the ultimate model. 
Table 2. Summary statistics of the continuous explanatory variables

\begin{tabular}{|c|c|c|c|c|c|c|c|}
\hline Variable & $\mathrm{N}$ & Min & $\operatorname{Max}$ & Mean & Std. D. & $\mathrm{CV}(\%)$ & $\mathrm{R}^{\mathrm{e}}$ \\
\hline Field area $\left(\mathrm{m}^{2}\right)$ & 351 & 200.00 & 21148.00 & 3237.70 & 3428.18 & 105.88 & $-0.165 * * *$ \\
\hline Score of field evaluation $^{\text {a }}$ & 349 & 0.00 & 38.90 & 32.13 & 4.56 & 14.18 & -0.076 \\
\hline Date of transplanting/sowing ${ }^{\mathrm{b}}$ & 351 & 1.00 & 70.00 & 33.66 & 13.98 & 41.55 & $-0.221 * * *$ \\
\hline Nitrogen from fertilizers $(\mathrm{kg} / \mathrm{ha})^{c}$ & 349 & 14.00 & 148.83 & 66.09 & 20.02 & 30.29 & 0.065 \\
\hline SPAD in panicle-forming stage & 351 & 26.30 & 63.30 & 36.06 & 4.26 & 11.82 & $0.185 * * *$ \\
\hline Stems per hill in panicle-forming stage & 351 & 13.80 & 34.60 & 24.34 & 4.18 & 17.15 & $0.236 * * *$ \\
\hline Plant height in panicle-forming stage $(\mathrm{cm})$ & 351 & 57.70 & 112.70 & 86.66 & 10.38 & 11.98 & $-0.226 * * *$ \\
\hline Individual LPV in panicle-forming stage & 351 & 2.60 & 6.00 & 4.39 & 0.58 & 13.31 & $0.248 * * *$ \\
\hline Community LPV in panicle-forming stage & 351 & 2.00 & 6.00 & 4.29 & 0.73 & 17.05 & $0.231 * * *$ \\
\hline SPAD in full-heading stage & 347 & 24.60 & 50.70 & 35.60 & 4.17 & 11.72 & $0.142 * * *$ \\
\hline Panicles per hill in full-heading stage & 347 & 13.30 & 42.40 & 23.52 & 4.36 & 18.55 & $0.191 * * *$ \\
\hline Plant height in full-heading stage (cm) & 347 & 79.50 & 117.60 & 102.61 & 6.71 & 6.54 & $0.157 * * *$ \\
\hline Individual LPV in full-heading stage & 347 & 2.60 & 6.20 & 4.47 & 0.67 & 14.98 & $0.121 * *$ \\
\hline Community LPV in full-heading stage & 344 & 2.00 & 6.00 & 4.31 & 0.73 & 17.02 & $0.225 * * *$ \\
\hline SPAD 10 days after full-heading & 350 & 20.10 & 46.80 & 34.93 & 3.86 & 11.05 & $0.207 * * *$ \\
\hline Panicles per hill 10 days after full-heading & 350 & 12.60 & 33.30 & 23.23 & 3.92 & 16.89 & 0.037 \\
\hline Plant height 10 days after full-heading $(\mathrm{cm})$ & 350 & 80.90 & 124.20 & 106.08 & 6.27 & 5.91 & $0.282 * * *$ \\
\hline Individual LPV 10 days after full-heading & 350 & 2.00 & 6.00 & 4.05 & 0.75 & 18.42 & $0.265 * * *$ \\
\hline Community LPV 10 days after full-heading & 350 & 2.00 & 6.00 & 4.02 & 0.74 & 18.40 & $0.299 * * *$ \\
\hline SPAD in maturity stage & 350 & 12.80 & 42.30 & 31.31 & 4.71 & 15.04 & $0.305 * * *$ \\
\hline Individual LPV in maturity stage & 350 & 1.00 & 6.40 & 3.18 & 0.79 & 24.79 & $0.254 * * *$ \\
\hline Community LPV in maturity stage & 350 & 1.00 & 6.00 & 3.13 & 0.82 & 26.22 & $0.198 * * *$ \\
\hline Panicles per hill in maturity stage & 350 & 12.80 & 33.50 & 23.12 & 3.86 & 16.72 & 0.072 \\
\hline Panicle length in maturity stage $(\mathrm{cm})$ & 349 & 16.90 & 23.80 & 19.99 & 1.23 & 6.14 & -0.067 \\
\hline Plant height in maturity stage & 350 & 65.60 & 99.30 & 83.95 & 5.87 & 7.00 & -0.076 \\
\hline Average temperature $\left({ }^{\circ} \mathrm{C}\right)^{d}$ & 351 & 23.42 & 27.49 & 25.91 & 1.01 & 3.88 & $-0.173 * * *$ \\
\hline Average solar radiation $\left(\mathrm{MJ} / \mathrm{m}^{2}\right)^{\mathrm{d}}$ & 351 & 12.80 & 22.91 & 18.81 & 3.00 & 15.94 & -0.032 \\
\hline $\mathrm{pH}$ & 347 & 5.42 & 6.56 & 6.12 & 0.18 & 3.01 & $-0.134 * *$ \\
\hline $\mathrm{EC}(\mathrm{ms} / \mathrm{cm})$ & 347 & 0.03 & 0.18 & 0.08 & 0.03 & 34.77 & $0.149 * * *$ \\
\hline Humus $(\%)$ & 345 & 1.46 & 12.33 & 5.63 & 1.81 & 32.15 & $0.127 * *$ \\
\hline Phosphate absorption coefficient (mg/100g) & 347 & 574.08 & 2689.26 & 1464.16 & 301.57 & 20.60 & 0.086 \\
\hline CEC (meq/100g) & 347 & 5.69 & 31.43 & 18.29 & 4.64 & 25.34 & 0.073 \\
\hline Ammonium nitrogen (mg/100g) & 347 & 0.16 & 2.27 & 0.65 & 0.28 & 42.63 & -0.080 \\
\hline Nitrate nitrogen (mg/100g) & 347 & 0.21 & 3.15 & 1.25 & 0.63 & 50.49 & -0.034 \\
\hline Effective phosphoric acid (mg/100g) & 347 & 1.02 & 29.45 & 7.74 & 5.26 & 67.90 & $0.213 * * *$ \\
\hline Exchangeable potassium (mg/100g) & 347 & 9.07 & 54.09 & 21.62 & 6.91 & 31.96 & -0.077 \\
\hline Exchangeable lime (mg/100g) & 347 & 90.91 & 561.62 & 303.25 & 79.77 & 26.30 & 0.046 \\
\hline Exchangeable magnesia (meq/100g) & 347 & 18.40 & 128.24 & 65.07 & 17.92 & 27.55 & $0.092 *$ \\
\hline Potassium saturation (\%) & 347 & 0.94 & 6.16 & 2.60 & 0.80 & 30.70 & $-0.166 * * *$ \\
\hline Lime saturation (\%) & 347 & 28.43 & 96.80 & 59.45 & 7.28 & 12.24 & -0.082 \\
\hline Magnesia saturation (\%) & 347 & 9.97 & 36.29 & 17.97 & 3.91 & 21.74 & -0.004 \\
\hline Lime/magnesia & 347 & 1.96 & 5.41 & 3.41 & 0.62 & 18.03 & $-0.092 *$ \\
\hline Magnesia/potassium & 347 & 2.64 & 18.62 & 7.54 & 2.74 & 36.35 & $0.110 * *$ \\
\hline Exchangeable manganese (\%) & 347 & 0.13 & 19.76 & 5.03 & 3.11 & 61.89 & 0.060 \\
\hline Soluble zinc (\%) & 347 & 2.50 & 76.69 & 8.70 & 6.37 & 73.15 & $-0.137 * *$ \\
\hline Soluble copper (\%) & 347 & 0.54 & 10.99 & 5.84 & 1.97 & 33.65 & -0.026 \\
\hline Free iron oxide (\%) & 347 & 0.32 & 3.42 & 1.73 & 0.57 & 32.71 & 0.073 \\
\hline Available silicic acid (mg/100g) & 347 & 6.70 & 68.54 & 29.54 & 11.47 & 38.84 & -0.086 \\
\hline
\end{tabular}

a: Evaluation items include variable concerning height difference, water depth, water leakage, former crop, water inletting, unevenness of soil fertility, illumination, and herbicides application; b: The earliest date of April 14=1, while the latest date of June 22=70; c: Calculation based on the amounts of chicken manure, chemical fertilizer, Ammonium sulfate and urea fertilizers, and the corresponding contents of nitrogen; d: Data of 20 days since full-heading; e: Pearson correlation with sorted brown rice; $* * *, * * *$ denote significant at $0.01,0.05$ and 0.10 , respectively

Source: survey conducted by the authors in 2014 


\section{VARIATION OF THE YIELDS AND RATIOS}

\section{General correlation and variation}

As shown in Table 1, CVs (Coefficients of variance) of the average yield per hectare, including those of the paddy with $15 \%$ moisture, unsorted and sorted brown rice, vary in the scope of $12-13 \%$. By contrast, the ratio $\mathrm{CVs}$, of both the unsorted brown rice against the paddy and the unsorted brown rice over the sorted brown rice, range around $3 \%$. Thus the yields fluctuate with much more variation than that of the ratios. With respect to the correlation correlations, the yield of sorted brown rice is identified as significantly correlating with the other four indicators shown in Table 3. Among them, coefficients with the two yields are larger than 0.95, much higher than those with the two ratios. It indicates that comparing the ratios, yield of sorted brown rice is much linearly related to the yield of paddy and unsorted brown rice. Fig. 1 plots the yield of the sorted brown rice and other yields and ratios, and it is clear that the yields scatter much closely to the estimated regression line, relate to the yield of the sorted brown rice.

\section{Variation among varieties}

Akidawara possesses the largest value of both the paddy yield converted by $15 \%$ of moisture, $7303 \mathrm{~kg}$ per hectare, and ratio of the unsorted brown rice in the paddy, $81 \%$. Consequently, its yield of unsorted brown rice is the highest valued amounting to $5934 \mathrm{~kg}$ per hectare. Simultaneously, Akidawara yields the highest amount of sorted brown rice with $5426 \mathrm{~kg}$ per hectare, despite the lowest ratio of sorted brown rice against unsorted brown rice, which is merely $91 \%$. In succession, the following higher yields are ranked as Akitakomachi, Ichibanboshi, Koshihikari and Yumehitachi. Being the relatively low-yielding varieties,

Table 3. Pearson correlation of the yields and ratios

\begin{tabular}{|c|c|c|c|c|c|}
\hline Yield and ratio & $\begin{array}{c}\text { Paddy of } 15 \% \\
\text { moisture } \\
(\mathrm{kg} / \mathrm{ha})\end{array}$ & $\begin{array}{l}\text { Unsorted brown } \\
\text { rice/paddy } \\
(\%)\end{array}$ & $\begin{array}{l}\text { Unsorted } \\
\text { brown rice } \\
\text { (kg/ha) }\end{array}$ & $\begin{array}{c}\text { Sorted/Unsorted } \\
\text { brown rice } \\
(\%)\end{array}$ & $\begin{array}{c}\text { Sorted } \\
\text { brown rice } \\
\text { (kg/ha) }\end{array}$ \\
\hline Paddy yield of $15 \%$ moisture (kg/ha) & 1.000 & & & & \\
\hline Unsorted brown rice/paddy (\%) & 0.071 & 1.000 & & & \\
\hline Yield of unsorted brown rice (kg/ha) & $0.963^{* * *}$ a & $0.334 * * *$ & 1.000 & & \\
\hline Sorted/Unsorted brown rice (\%) & 0.001 & $-0.267 * * *$ & -0.067 & 1.000 & \\
\hline Sorted brown rice $(\mathrm{kg} / \mathrm{ha})$ & $0.951 * * *$ & $0.263^{* * *}$ & $0.969 * * *$ & $0.178 * * *$ & 1.000 \\
\hline
\end{tabular}
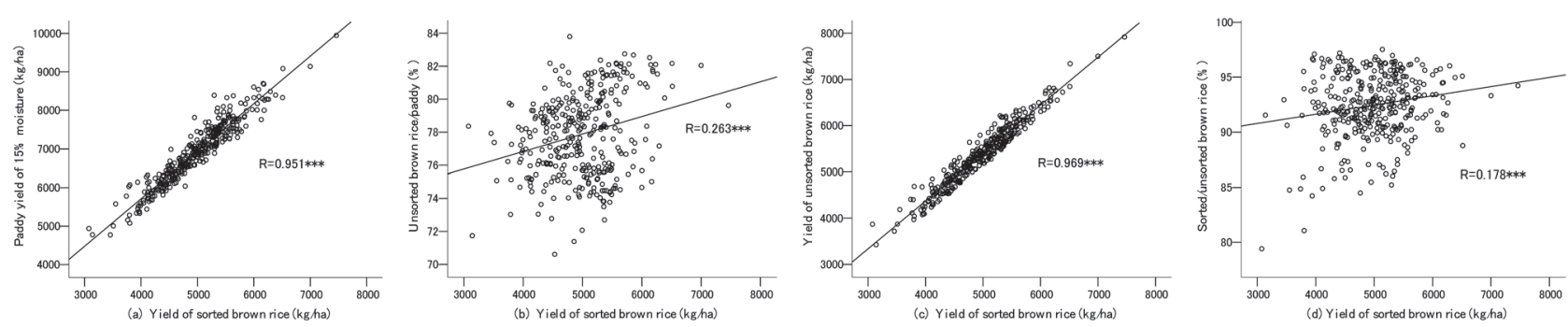

Fig. 2. Scatters of sorted brown rice yield and other yields and ratios.

(***: Pearson coefficient significant at 0.01 )

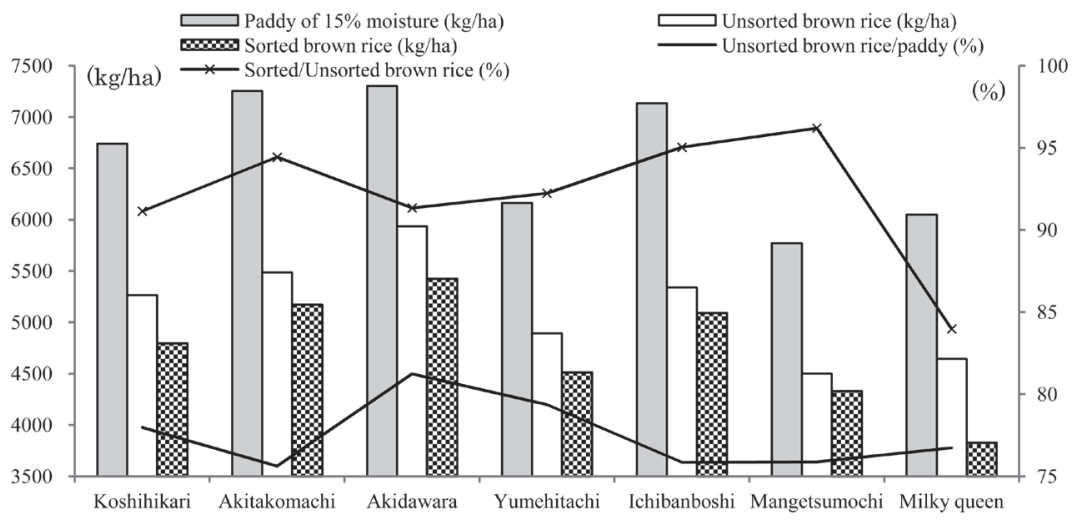

Fig. 3. Rice yields and ratios among varieties. 
Mangetsumochi has the lower yield of both the paddy and unsorted brown rice than Milky queen. Nevertheless, the former yields more sorted brown rice per hectare than the latter, thanks to the highest ratio of sorted brown rice to the unsorted brown rice (Fig. 3).

\section{Variation among cultivation methods}

The conventional transplant has the highest yields of both paddy and sorted brown rice per hectare, with the amount of $7053 \mathrm{~kg}$ and $5105 \mathrm{~kg}$, respectively. The two yields per hectare are ranked secondly with submerged direct sowing, and the values are $6940 \mathrm{~kg}$ and $5057 \mathrm{~kg}$, respectively. Meanwhile, it yields the highest amount of unsorted brown rice, $5619 \mathrm{~kg}$ per hectare, thanks to the highest ratio of $81 \%$ of the unsorted brown rice in the paddy. Well-drained direct sowing possesses the highest ratio of $97 \%$ sorted brown rice within the unsorted grains; while its average yield of $4846 \mathrm{~kg}$ sorted brown rice per hectare is ranked the third, due to the lowest paddy yield (Fig. 4).

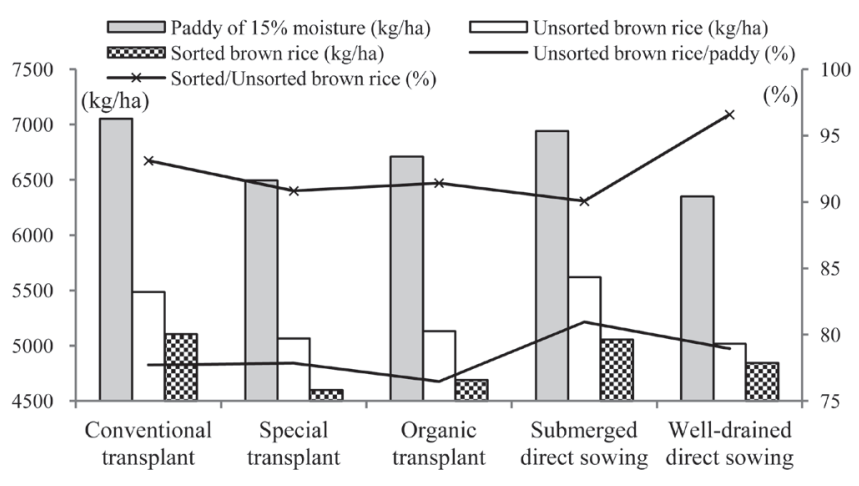

Fig. 4. Rice yields and ratios among cultivation methods.

\section{Variation among soil types}

Little discrepancy can be identified between the two soil types, with respect to all the yields and ratios. In general, rice planted in the gray lowland soil yields more than that of the peat soil, while the average ratios of the latter are higher than the former. In the paddy fields with gray lowland soil, yields per hectare of the paddy, unsorted and sorted brown rice are $7069 \mathrm{~kg}, 5464 \mathrm{~kg}$ and $5030 \mathrm{~kg}, 2.6 \%, 1.6 \%$ and $1.2 \%$ higher than that of the peat soil, respectively. At the same time, in the former

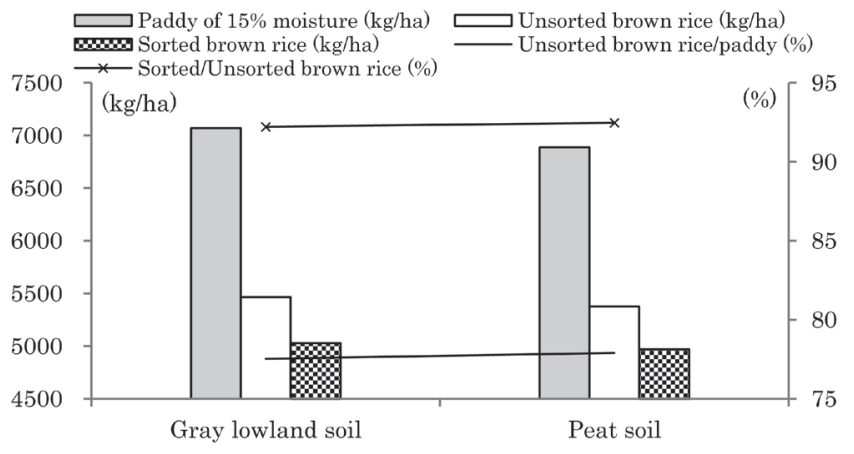

Fig. 5. Rice yields and ratios among soil types. type of soil, there is $77.5 \%$ of the unsorted brown rice within paddy and $92.2 \%$ of sorted brown rice in the unsorted ones, on average. Both of the two ratios are lower than that of the paddy fields of peat soil, although the differences are no more than 0.5\% (Fig. 5).

\section{RESULT AND DISCUSSION}

As mentioned above, rice yield in Japan is mainly measured by the weight of sorted brown grain, which is directly relating to the milled rice sold in the market. For each continuous variable, we present the Pearson correlation coefficient and the significance with sorted brown rice yield in Table 2 . These coefficients measure linear association between each determinant and the yield, showcasing how strongly the two variables are linearly related and be referential to identify the determinants of some variables. However, correlation coefficient may lead to illusive results as it showcases only the bilateral relationship, without considering the influence of other variables. Thus to identify the yield determinants of the sorted brown rice, we need to conduct multivariate regression analysis. Hereby, we can get significant models and determinants, partial correlation coefficients of which showcase the pure impact holding the influence of other variables constant (Gujarati and Porter, 2010: p254). To amplify the relationships among yield and the determinants, logarithmic transformation is adopted to the continuous variables.

\section{Results of the multivariate regression}

In the initial multivariate regression model, the independent variables included all the continuous and discrete variables shown in Table 2 and Table 3. For each discrete variable, a dummy variable is formulated taking the value 1 or 0 to indicate the presence or absence of the categorical effect. According to the estimation result of the final model, nine continuous and three discrete variables are included in the final model (Table 4). Value of the adjusted $\mathrm{R}^{2}$ denotes that $37.5 \%$ of the variation of the independent variable can be explained by the 12 significant independent variables, for this sample of 334 paddy fields. The significant values of $\mathrm{F}$ and $\mathrm{t}$ show that, both the model and each dependent variable made difference in identifying the variation. VIFs of all the dependent variables are less than 10, hence eliminated the probability of Collinearity. In the plot of regression standardized residual shown in Fig. 6, the expected cumulated probability increases closely as the observed cumulated probability increases. Thus it indicates that heteroscedasticity does not exist in the final model (Carter et al., 2012).

In Table 4, column B contains the unstandardized estimated regression coefficients. For each continuous variable $\left(X_{\mathrm{i}}\right)$, the coefficient is the elasticity of yield with respect to $X_{\mathrm{i}}$. For instance, the plus coefficient of $X_{1}$ and the minus coefficient of $X_{2}$ imply that yield can be increased by either more panicles per hill in the fullheading stage or earlier transplanting or sowing. For a certain level, $1 \%$ increase of panicle number can increase 
Table 4. Result of the Log-linear Multivariate Regression estimation

\begin{tabular}{|c|c|c|c|c|c|c|}
\hline Independent variable ${ }^{a}$ & $\mathrm{~B}^{\mathrm{b}}$ & $\Delta \%^{\mathrm{c}}$ & Std. B & $\begin{array}{c}\text { Contribution } \\
(\%)^{\mathrm{d}}\end{array}$ & $\mathrm{t}$ & VIF \\
\hline (Constant) & 7.803 & & & & 37.053 & \\
\hline Panicles per hill in full-heading stage $\left(X_{1}\right)$ & $0.196 * * *$ & 0.195 & 0.297 & 14.558 & 4.860 & 1.995 \\
\hline Date of transplanting/sowing $\left(X_{2}\right)$ & $-0.053 * * *$ & -0.053 & -0.212 & 10.371 & -2.931 & 2.785 \\
\hline Lime/magnesia $\left(X_{3}\right)$ & $-0.100 * * *$ & -0.100 & -0.145 & 7.120 & -2.830 & 1.408 \\
\hline Nitrogen from fertilizers per ha $\left(X_{4}\right)$ & $0.046 * *$ & 0.046 & 0.107 & 5.232 & 1.983 & 1.549 \\
\hline Community LPV in panicle-forming stage $\left(X_{5}\right)$ & $0.065^{* *}$ & 0.065 & 0.100 & 4.880 & 2.120 & 1.178 \\
\hline Humus $\left(X_{6}\right)$ & $0.036 *$ & 0.036 & 0.098 & 4.811 & 1.657 & 1.875 \\
\hline Field area $\left(X_{7}\right)$ & $0.014 *$ & 0.014 & 0.090 & 4.415 & 1.719 & 1.467 \\
\hline Exchangeable potassium $\left(X_{8}\right)$ & $-0.034 *$ & -0.034 & -0.086 & 4.194 & -1.661 & 1.417 \\
\hline Exchangeable manganese $\left(X_{9}\right)$ & $0.014 *$ & 0.014 & 0.079 & 3.847 & 1.670 & 1.180 \\
\hline Akidawara $\left(D_{1}\right)$ & $0.153 * * *$ & 16.537 & 0.484 & 23.706 & 9.102 & 1.509 \\
\hline Milky queen $\left(D_{2}\right)$ & $-0.201 * * *$ & -18.198 & -0.197 & 9.658 & -4.174 & 1.191 \\
\hline Well-drained direct sowing $\left(D_{3}\right)$ & $-0.236 * *$ & -21.025 & -0.147 & 7.210 & -2.422 & 1.971 \\
\hline
\end{tabular}

Dependent Variable $(Y)$ : Natural log of the sorted brown rice yield; Valid $\mathrm{N}=334$

$\mathrm{R}=0.631, \mathrm{R}^{2}=0.398$, Adjusted $\mathrm{R}^{2}=0.375 ; \mathrm{F}(12,321)=17.682^{* * * *}$

a: Natural log values of $X_{i}, \mathrm{~b}$ : ***,** and *imply significant at the level of $0.01,0.05$ and 0.10 , respectively; c: percentage of paddy yield changes due to a $1 \%$ increase of $X_{i}$ by $=100 *\left(1.01^{\mathrm{B}}-1\right)$; and due to value of $D$ shifting from 0 to 1 by $100^{*}\left(\mathrm{e}^{\mathrm{B}}-1\right)$; d: calculated based on Std. B.

Software: SPSS 23.0; Variable selection: the Backward procedure

the yield by $0.196 \%$, while $1 \%$ decrease of the transforming or sowing date value can increase the yield by $0.053 \%$, holding other variables fixed. For exacter calculation, the estimated yield increases by $1.01^{0.196}$ $1=0.195 \%$ and $1.01^{-0.053}-1=-0.053 \%$, respectively (Wooldridge, 2013: p183). Similarly, as the other significant determinants, $1 \%$ increase of the nitrogen amount, community LPV in panicle-forming stage, humus contains, field area and exchangeable manganese are estimated to increase the yield by roughly $0.046 \%, 0.065 \%$, $0.036 \%, 0.014 \%$ and $0.014 \%$, respectively. Meanwhile, $1 \%$ decrease of ratio of the lime to magnesia and exchangeable potassium, ceteris paribus, are measured as increasing the yield by roughly $0.1 \%$ and $0.034 \%$, respectively. Table 4 shows the exacter percentage of yield changes due to $1 \%$ increase of each $X_{\mathrm{i}}$ as well. For a dummy independent variable $D_{i}$, the coefficient B implies yield changes by $\mathrm{e}^{\mathrm{B}}-1$ when $D_{\mathrm{i}}$ switches from 0 to 1 , keeping other explanatory variables constant (Wooldridge, 2013: pp224-225). Thus for Akidawara, the coefficient of 0.153 denotes a roughly $15.3 \%$ higher yield, while the exact increase is $16.537 \%$. By the same token, milky queen and well-drained direct sowing showcase roughly $20.1 \%$, and $23.6 \%$ less of yield on average, respectively, holding other factors fixed (Table 4).

Within the continuous variables, an unstandardized coefficient B is affected by the units of measurement. We need to calculate standardized coefficient, absolute values of which show relative importance of the explanatory variables. For example, according to data of column Std. B in Table 4, the panicle number in full-heading stage is measured as the most effective continuous factor to affect yield of the sorted brown rice. Variables in
Table 4 are presented in the ascending rank of the absolute values of the Std. B, grouped in continuous and discrete variables.

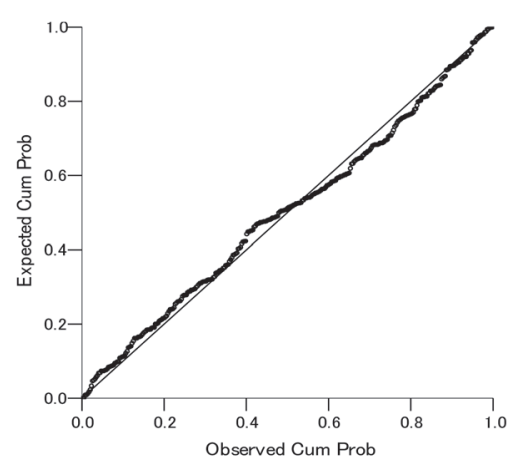

Fig. 6. Plot of regression standardized residual.

\section{Discussion on impact of the continuous determi- nants}

(1) Full-heading stage refers to when $40-50 \%$ of the stalks have finished sprouting panicles. It is an important stage to judge the growth, variety properties of the whole year (Goto et al., 2000). Thereafter, focus of cultivation management shifts from the growth of stem and leaves, to panicle growth and grain filling. In this stage, more panicles help to increase the yield directly according to the determining of rice yield. It is proofed by Fig. 7-(a), where the yield of sorted brown rice is plotted to go upward with larger panicle numbers. (2) Relatively earlier transplanting or sowing benefits high yielding. Generally, earlier transplanting or sowing is followed by 
longer vegetation period to accumulate more nutrients and benefit the growth in the following stages. In another study (Li et al., 2015), we have identified that growth duration goes shortened, when the transplanting or sowing time goes relatively later. e.g., the paddy transplanted during April 11-20 can grow for 109 days before heading, while those transplanted or sowed during June 21-30 can grow only for 58.5 days on average. The shortened vegetative growth usually results in reduced panicles, spikelet and poor ripening ratio, etc (NARO, 2011). Fig. 7-(b) verified the trend of downward yield when transplanting or sowing time goes later. (3) Magnesia is the key ingredient of chlorophyll and thus indispensible for photosynthesis, in addition to balance the soil minerals. Nevertheless, its absorption efficiency is suppressed when soil contains excessive lime. As shown in Fig. 7-(c), a positive correlation relationship, with the significant level of 0.01 , exists between the magnesia saturation and the yield of sorted brown rice. (4) As an essential element for paddy growth, nitrogen exists mainly in forms of protein especially Rubisco, which accounts for 20-30\% of total nitrogen amount (CSSJ, 2002: p126). Generally, sufficient nitrogen helps to increase the yield, as shown in Fig. 7-(d), through the enhancement of photosynthesis. More than $90 \%$ of crop biomass is derived from photosynthesis, and rice has been found possessing high photosynthesis rate 10 times of some evergreen trees (Makino, 2011). Therefore, it positively relates to yield through increasing nitrogen appropriately, with the amount leading to no lodging and other negative consequences. (5) The panicle-forming stage refers to when the young panicle growth to the length of $1-2 \mathrm{~mm}$ that visible by naked eye. It is a very important stage in determining the optimum fertilizer amount and conducting the paniclelength diagnosis. In addition, the importance of prevention cold injury increases after this stage. To judge the nutrition contains and hence decide the top dressing amount, there is a quick way of reading the leaf plate value (LPV), higher grade of which indicates more nutrition contains in the plant. Thus this indicator is positive relate to yield, as plotted in Fig. 7-(e). (6) As kind of polymeric compound transformed from organic matter, humus composes an important source of supplying the paddy plant with carbon, hydrogen, oxygen, nitrogen, sulfur, phosphorus and other nutrient elements (Makino, 1998). Humus can significantly improve the soil's cation exchange capacity, hence contributes to store nutrient against leached by rain or irrigation. On the other hand, humus can hold moisture up to $80-90 \%$ of its weight, and thus makes the soil strong to withstand drought conditions. The biochemical structure enables humus to improve soil aeration, block the toxic substances excess nutrients, and excessive acid or alkaline (Kono, 1993). Thus as shown in Fig. 7-(f), humus is positively correlating to the yield of sorted brown rice, significant at 0.05. (7) The inverse impact of exchangeable potassium, as shown in Fig. 7-(g), reveals the reality that over the latest years, surplus potassium is accumulated in paddy field of Japan, due to the over-application of fertilizers (Watanabe et al., 2015). Within the sampled paddy fields, the average potassium saturation amounts to $2.6 \%$, higher than the maximum threshold of $2.5 \%$ of paddy field in Ibaraki Prefecture (MAFF, 2008). (8) As an essential trace element for plant growth, manganese is involved in photosynthesis and the transformation of nitrogen, and being active in the catalysis of many enzymes and redox processes. It can promote the synthesis of chlorophyll and the operation of carbohydrates. The deficiency of manganese in soil may lead to withered plants, dysplasia, and eventually declined production. Thus, a positively relationship exists between the amount of exchangeable manganese and the yield of sorted brown rice, as shown in Fig. 7-(h).

Within this sample, 312 fields are less than 0.7 ha, up to which positive correlation coefficients are observed
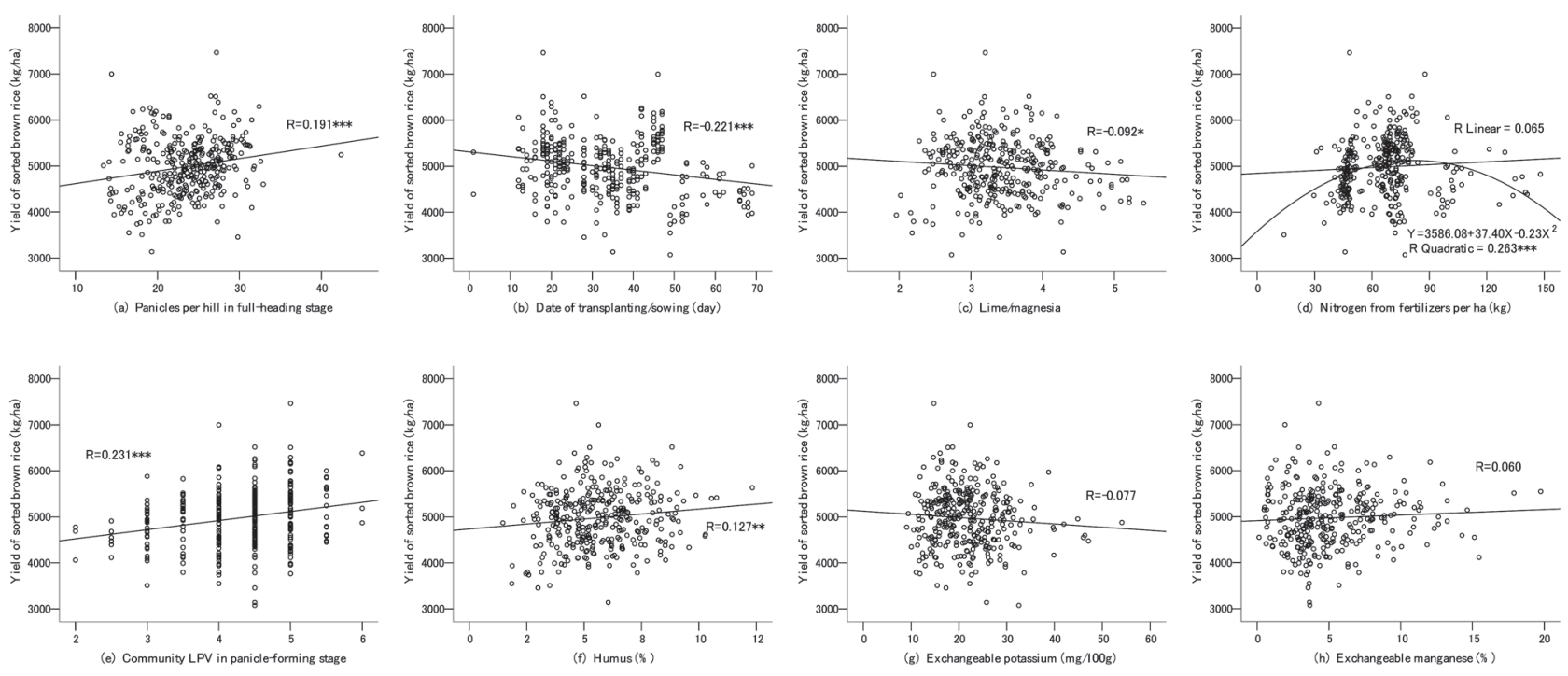

Fig. 7. Scatters of sorted brown rice yield and determinants.

(***, **, *: Pearson coefficient significant at $0.01,0.05$ and 0.10 , respectively) 
between the yield of sorted brown rice and field area (Fig. 2). It can be interpreted by that when fields scaled less than approximately 0.7 ha, larger area usually can increase yield through enlarged sink size, i.e., spikelet number per unit land area. Meanwhile, the correlation coefficient of the field area and amount of nitrogen from fertilization is 0.46 , significant at 0.01 , indicating that larger field facilitates the application of fertilizer. Nevertheless, both of the factors indicate the existence of diminishing returns when being inputted over certain threshold values. As shown in Fig. 4-(d) and Fig. 8, yield per hectare decreases in the paddy fields more than roughly $0.7 \mathrm{ha}$, or when the amount of nitrogen amount exceeds approximately $80 \mathrm{~kg}$ per hectare.

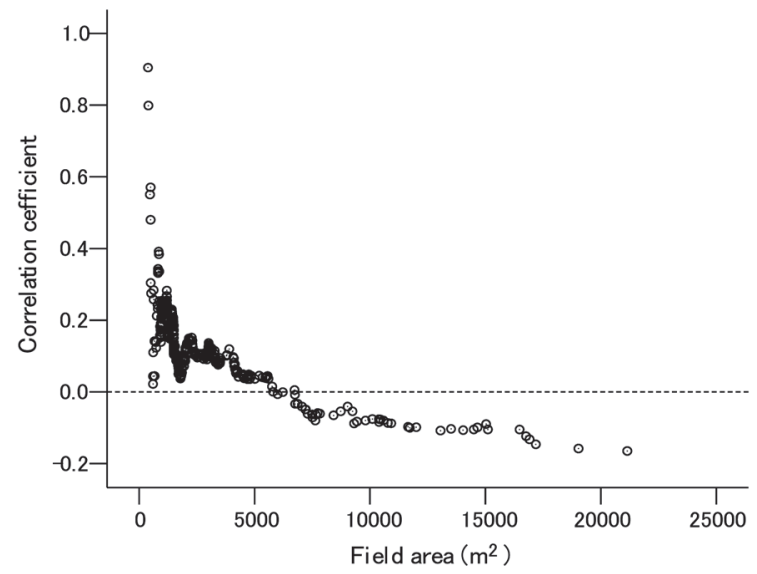

Fig. 8. Correlation coefficient of field area and sorted brown rice yield.

\section{Discussion on impact of the discrete determinants}

As we have measured in another study (Li et al., 2015), variety is a significant factor affecting paddy yield of this sample. Being a new, lodging-resistant and highyielding variety, Akidawara is suitable to be cultivated in the Kanto region. In this study, Akidawara yields $7303 \mathrm{~kg}$ per hectare on average, the highest among the seven varieties. The average yield of other six varieties is $6812 \mathrm{~kg}$ per hectare, $7.21 \%$ lower than that of Akidawara (Table 3). Meanwhile, Akidawara has the longest growth of 80 days from transplanting to heading, almost 10 day longer than that of the other varieties on average. Thus as analyzed above, it has advantage in prolonged vegetative growth with more panicles, spikelet and enlarged ripening ratio, etc. By contrast, milky queen is a new rice variety bred from Koshihikari, with low amylose content in the endosperm. Milky queen was not adapted to heavy chemical fertilizer use in paddy fields, because it was susceptible to lodging after heading and to leaf-blast and panicle-blast disease. In addition, milky queen is weak in resistance to rice blast disease (Isei et al., 2001). Therefore, as shown in Fig. 3, the sorted brown rice yield of milky queen is $3829 \mathrm{~kg}$ per hectare, the lowest among the seven varieties.

Direct sowing is one of the traditional cultivation methods, and it is outstanding in saving the input of labors and energy. However, due to the defects of instable establishment, poor resistance to weed damage and lodging occurrence, directly sowed rice yields lower than the transplanting ones, in general cases. With respect to the well-drained direct sowing, it possesses more defects of sowing time is dominated by the weather, nutrient loss from cracked soil, etc (CSSJ, 2002: p326329). Viewing back to the survey data, yield of the paddy cultivated using well-drained direct sowing is the lowest, with the largest data dispersion denoted by CV, among the five cultivation methods. In addition, it has the smallest number of panicles in the heading stage. Submerged direct sowing is used only to cultivate Akidawara, within which the average yield of submerged direct sowing is less than the other cultivation methods.

\section{CONCLUSION}

In the initial multivariate regression analysis, the candidate determinants included a variety of continuous variables of the yield, field characteristics, transplanting time, nitrogen amounts from fertilizing, and growth data of different stages. In addition, three discrete variables are included, from the perspectives of variety, cultivation method and soil type. Result of the multivariate regression analysis shows that, the panicle numbers in heading stage and earlier transplanting date are the most important determinants to increase rice yield. The other significant determinants include nitrogen amount, humus content, exchangeable manganese, and community LPV in panicle-forming stage, all of which have positive impact on yield of sorted brown rice; ratio of lime to magnesia and exchangeable potassium are positive with yield of sorted brown rice. Within the discrete determinants, Akidawara and Milky queen are measured as high-yield and low-yield variety, respectively; while the well-drained direct sowing is identified as negatively affecting the yield of sorted brown rice. The regression coefficients indicate positive impacts of field area to yield, while the correlation coefficient and further analysis from scatter plot denote over-large values may lead to yield reduction.

These empirical findings are referential to increase yield in farm management. Nevertheless, paddy production within large-scale farms is a systematic procedure, subject to constraints of the labors, funds, machinery, etc. For instance, although earlier transplanting or sowing has been measured as favorite higher yield, it may be unrealistic or uneconomic to conduct transplanting or sowing in many fields simultaneously. Thus optimal planning is necessary to conduct transplanting or sowing in different time and makes full use of the limited machinery, labors and funds (Chomei et al., 2015). Meanwhile, the appropriate amount of fertilizer, and the rational allocation of fields with different areas need to be optimized in the following studies, considering the property of different varieties. As analyzed above, the adoption of direct sowing negatively relates to yield increasing, but it possesses attributes in agreement with the sustainable development. Hence, much more paddy 
varieties suitable for direct sowing needed to be bred and adopted.

\section{ACKNOWLEDGEMENT}

This research (NoshoNavi1000) is supported by grants from the Project of the NARO Bio-oriented Technology Research Advancement Institution (The Special Scheme to Create Dynamism in Agriculture, Forestry and Fisheries through Deploying Highly Advanced Technology).

\section{REFERENCES}

Carter, R. H., E. G. William and C. L. Guay 2012 Principles of Econometrics (4 ${ }^{\text {th }}$ ed.), Hoboken (NJ), p. 303

Chomei, Y., T. Nanseki and S. Aga, M. Miyazumi 2015 Relationship between the managerial goals, revenue and costs in large-scale paddy farm: optimization analysis considering the operational risks, Proceeding of annual symposium of the JSAI, pp. 12-13 (in Japanese)

CSSJ (Crop Science Society of Japan) 2002 Encyclopedia of Crop Science, Asakura Publishing Co., Ltd., Tokyo (Japan), pp. 126, 210, 326-329, 522 (in Japanese)

Goto, Y., Y. Nitta 2000 Crops I: Paddy Cultivation, Japan Agricultural Development and Extension Association (JADEA), Tokyo (Japan), p. 120 (in Japanese)

Gujarati, D. N. and D. C. Porter 2010 Essentials of Econometrics ( $4^{\text {th }}$ ed.), McGraw-Hill, New York (the U.S.), p. 254

Gujarati, D. N. 2015 Econometrics by Example (2 ${ }^{\text {nd }}$ ed.), Palgrave, London (England), p.44

Ise, K., Y. Akama, N. Horisue, A. Nakane, M. Yokoo, I. Ando, T. Hata, M. Suto, K. Numaguchi, H. Nemoto, H. Furutachi and T. Imbe 2001 Milky queen, a new high-quality rice cultivar with low amylose content in endosperm, Bulletin of NARO Institute of Crop Science (NICS), 2: 39-61 (in Japanese)

Isemura, H., H. Hisamoto, S. Yokota, T. Butta, Y. Fukuhara, K. Takasaki and T. Nanseki 2015 Field demonstration on the paddy yield measurement and operation video recording, Proceeding of the Annual Symposium of the JSAI, pp. 28-29 (in Japanese)

JEN (Japan Economic News) 2013 The government decided to abolish the rice acreage reduction policy in 5 years, Nov. 26: http://www.nikkei.com/article/DGXNASFS2600F_W3A121C1MM0000/ (in Japanese)

JSAI (Japan Society of Agricultural Informatics) 2014 Smart Agriculture: Innovation and sustainability in Agriculture and Rural Areas, Agriculture \& Forestry Statistics Publishing Inc., Tokyo (Japan), pp. 128-149 (in Japanese)

Ju, C., R. J. Buresh, Z. Wang, H. Zhang, L. Liu, J. Yang and J. Zhang 2015 Root and shoot traits for rice varieties with higher grain yield and higher nitrogen use efficiency at lower nitrogen rates application, Field Crop Research, 175: 47-55

Kono, E. 1993 Humus, Japanese Journal of Agricultural Engineering, 61(12): 56 (in Japanese)

Li, D., T. Nanseki and Y. Chomei 2014 Managerial models of smart paddy agriculture and the adoption of GAP in Japan, Proceeding of the $8^{\text {th }}$ International symposium on the East
Asian Environmental Problems (EAEP), Hanashoin Press, Fukuoka (Japan), pp. 130-135

Li, D. T. Nanseki, Y. Matsue, Y. Chomei and S. Yokota 2015 Impact assessment of the varieties and cultivation methods on paddy yield: evidence from a large-scale farm in the Kanto Region of Japan, J. Fac. Agr., Kyushu Univ., Japan, 60(2): $529-534$

MAFF 2014a Statistics on incomes from agricultural production: http://www.maff.go.jp/j/tokei/kouhyou/nougyou_sansyutu/ (in Japanese)

MAFF 2014b Statistics of food self-sufficiency: http://www. maff.go.jp/j/tokei/sihyo/data/02.html (in Japanese)

MAFF 2014c Statistics on agricultural management of production costs: http://www.maff.go.jp/j/tokei/sihyo/data/12-2.html (in Japanese)

MAFF 2014d Present situation and countermeasures of rice production costs: https://jataff.jp/project/inasaku/koen/koen_h25_2 pdf (in Japanese)

MAFF 2014e Data of agricultural production corporations: http://www.maff.go.jp/j/keiei/koukai/sannyu/pdf/seisan.pdf (in Japanese)

MAFF 2014f Inspection standards of brown rice: http://www. maff.go.jp/j/seisan/syoryu/kensa/kome/k_kikaku/index.html (in Japanese)

MAFF 2015 Statistics on the crops planted in 2014: http://www.e-stat.go.jp/SG1/estat/List.do?lid=000001129556 (in Japanese)

Makino, A. 2011 Photosynthesis, grain yield, and nitrogen utilization in rice and wheat, Plant Physiology, 155: 125-129

Makino, T. 1998 Humus and its function: Japanese Journal of Agricultural Engineering, 66(1): 82 (in Japanese)

Muazu, A., A. Yahya, W. I. W. Ishak and S. Khairunniza-Bejo 2014 Yield prediction modeling using Data Envelopment Analysis methodology for direct sowing, wetland paddy cultivation, Agri. and Agri. Sci. Proc., 2: 181-190

Nanseki, T. 2015 ICT application in the research project of NoshoNavi1000, Proceeding of annual symposium of the JSAI, pp. 10-11 (in Japanese)

NARO 2011 Technical precautions upon the late transplanting rice: http://www.naro.affrc.go.jp/nics/webpage_contents/ sinsai/banshoku/index.html (in Japanese)

NIAES (National Institute for Agro-Environmental Sciences) the Soil Information Navigation System: http://agrimesh.dc. affrc.go.jp/soil_db/index.phtml (in Japanese)

Nishiura, Y. and Wada, T. 2012 Rice cultivation by direct sowing into untilled dry paddy stubble: panicle number and rice yield, $E A E F, \mathbf{5}(2): 71-75$

Ohizumi, K. 2014 Analysis on the perspective agriculture of Japan, NHK Books Tokyo (Japan), pp. 16-18(in Japanese)

PMJHC (Prime Minister of Japan and His Cabinet) 2014 Japan Revitalization Strategy: Japan's challenge for the future: http://www.kantei.go.jp/jp/singi/keizaisaisei/pdf/honbunEN.pdf

USDA 2014 Current costs and returns of rice: http://www.ers. usda.gov/data-products/commodity-costs-and-returns.aspx

Wooldridge, J. M. 2013 Introductory Econometrics: A Modern Approach, $5^{\text {th }}$ Int'l Ed., Cengage Learning, pp. 183, 224-225

Yaguchi, K. 2012 Several issues on the Expanding scales of agricultural management and land integration: approaching to the TPP, Issue Brief of Japan National Diet Library, 737: 1-12 (in Japanese) 